\title{
Utilização de estruturas secretoras na identificação dos gêneros de Asteraceae de uma vegetação de cerrado ${ }^{1}$
}

\author{
MARÍLIA DE MORAES CASTRO², HERMÓGENES DE FREITAS LEITÃO-FILHO² e \\ WALKYRIA ROSSIMONTEIRO3
}

(recebido em 02/05/96; aceito em 04/03/97)

\begin{abstract}
The use of secretory structures for identification of genera of Asteraceae from cerrado vegetation). In order to verify the possible taxonomic value of secretory structures in species of Asteraceae, structure types were surveyed in leaves of 72 representatives of this family occuring in cerrado vegetation in the Reserva Biológica de Moji Guaçu (São Paulo state, Brazil). Leaves were selected and prepared using the normal techniques for herbarium material; whole leaves were cleared and stained, and hand-cut section made in the median region. Ducts, idioblasts, hydathodes and 10 different kinds of trichomes were found. When these structures are considered, they are all of diagnostic value at generic level, and it was possible to construct a key to the genera occurring in cerrado vegetation. At tribal level, the data from the present survey suggest affinities between representatives of Eupatorieae and Heliantheae, and show the Vernonieae to be relatively homogeneous; these affinities were based on presence and absence of the various types of secretory structures and their position on the leaves.

RESUMO - (Utilização de estruturas secretoras na identificação dos gêneros de Asteraceae de uma vegetação de cerrado). Com o objetivo de se verificar o possível valor taxonômico das estruturas secretoras para espécies de Asteraceae, foi efetuado um levantamento de tipos destas estruturas em folhas de 72 representantes da referida família, que compõem parte da vegetação do cerrado da Reserva Biológica de Moji Guaçu (São Paulo, Brasil). As folhas foram selecionadas e tratadas segundo as técnicas usuais empregadas para materiais herborizados; a região mediana destas peças foi cortada a mão livre, enquanto que folhas inteiras foram diafanizadas e coradas. O levantamento evidenciou ductos, idioblastos, hidatódios e 10 diferentes tipos de tricomas secretores. Avaliados conjuntamente, os tipos de estruturas secretoras têm valor diagnóstico em nível genérico, o que permitiu a elaboração de uma chave para identificação dos gêneros desta vegetação de cerrado. Algumas considerações foram efetuadas em nível de tribo, sugerindo-se uma possível afinidade entre os representantes das tribos Eupatorieae e Heliantheae, e evidenciandose a homogeneidade observada para os elementos constitutivos da tribo Vernonieae; nestes casos, considerou-se a ausência ou a presença dos diferentes tipos de estruturas secretoras e a posição que ocupam nos órgãos foliares.
\end{abstract}

Key words - Asteraceae, secretory structures, leaf, cerrado vegetation

\section{Introdução}

O estudo das estruturas secretoras tem se mostrado relevante para o conhecimento de sua anatomia, da natureza química do exsudato e do papel que desempenham no corpo do vegetal (Lüttge 1971, Schnepf 1974, Esau 1977, Cutter 1978, Fahn 1979, 1988).

O mesmo tipo de estrutura secretora pode estar presente em todos os órgãos da planta ou pode estar confinado a apenas um órgão (Solereder 1908, Fahn 1979); pode-se encontrar, ainda, diferentes tipos nas

1. Parte da tese de doutorado de M. de M. Castro. Instituto de Biociências, Universidade de São Paulo.

2. Departamento de Botânica, Instituto de Biologia, Universidade Estadual de Campinas, Caixa Postal 6109, 13083-970 Campinas, SP, Brasil.

3. Departamento de Botânica, Instituto de Biociências, Universidade de São Paulo, Caixa Postal 11461 05422-970 São Paulo, SP, Brasil. partes de um mesmo vegetal (Solereder 1908, Esau 1977, Fahn 1979).

Para a folha, considerando-se as Asteraceae, as investigações realizadas relataram a presença de oito diferentes tipos de estruturas secretoras: ductos (Fueyo 1986, Castro 1987, Maksymowych \& Ledbetter 1987, Ascensão \& Pais 1988, Joseph et al. 1988, Lersten \& Curtis 1988, Meira 1991, Claro 1994), cavidades (Curtis \& Lersten 1986,1990, Fueyo 1986, Monteiro 1986, Lersten \& Curtis 1986, 1987, 1989, Monteiro et al. 1995), idioblastos (Castro 1987, Meira 1991, Claro 1994), laticíferos (Vertrees \& Mahlberg 1978), hidatódios (Perrin 1971, Lersten \& Curtis 1985, Castro 1987, Meira 1991, Claro 1994), nectários extraflorais (O’Dowd \& Catchpole 1983), tricomas (Carlquist 1958, Kelsey \& Shafizadeh 1980, Werker \& Fahn 1981,1982, Ascensão \& Pais 1982,1987, Castro 1987, Meira 1991, Duke \& Paul 1993, Claro 1994) e apêndices glandulares (Carlquist 1959a, b); nestes trabalhos, tais estruturas foram investigadas quanto 
aos aspectos estruturais, ultra-estruturais, histoquímicos e ecológicos.

As estruturas secretoras variam amplamente em sua morfologia e anatomia, e podem representar um importante caráter taxonômico devido, especialmente, à posição constante que ocupam nas espécies e variedades em que ocorrem (Solereder 1908, Metcalfe \& Chalk 1950, Fahn 1979, 1988). De acordo com os dados de literatura, estas estruturas podem estar limitadas a certas famílias (Pyykko 1966) e a certos gêneros (Pyykko 1966, Lersten \& Curtis 1993, 1995) ou podem ser significantes em nível subgenérico, de grupo (Lersten \& Curtis 1994) ou mesmo em nível específico (Maleci \& Marchi 1983, Kelsey 1984, Doaigey \& Harkiss 1991, Maleci \& Servettaz 1991).

O presente trabalho, realizado sobre as Asteraceae ocorrentes em uma vegetação de cerrado, tem como objetivo a verificação da validade das estruturas secretoras em folhas como subsídio para a taxonomia da referida família.

\section{Material e métodos}

O levantamento dos tipos de estruturas secretoras em folhas foi efetuado em 72 espécies de Asteraceae que compõem a vegetação de cerrado (Mantovani \& Martins 1993) na Reserva Biológica de Moji Guaçu (São Paulo, Brasil); as áfilas e as consideradas invasoras foram excluídas.

As espécies estudadas estão depositadas no Herbário do Instituto de Botânica de São Paulo (SP), exceto Vernonia ferruginea Less., encontrada no Herbário da Universidade Estadual de Campinas (UEC). Materiais referentes Inulopsis scaposa (Baker) Hoff. e Trixis verbasciformis Less. foram obtidos de vegetação de cerrado pertencente a outras regiões do estado de São Paulo, pois aqueles coletados na Reserva não estavam disponíveis na época em que o presente trabalho foi desenvolvido. Os dados de herbário estão relacionados na tabela 1.

Os critérios estabelecidos para seleção das folhas utilizadas foram: o comprimento por elas atingido e o estado de preservação do material herborizado; em cada espécie, a maior folha encontradas nas exsicatas foi avaliada quanto ao seu comprimento e as selecionadas apresentavam medidas que variavam na faixa de metade a um terço dos valores máximos encontrados.

O material botânico foi fervido em água destilada até que submergisse, tratado com hidróxido de potássio $2 \%$ à temperatura ambiente (Smith \& Smith 1942) e desidratado em álcool etílico em série crescente até $70 \%$. Parte das folhas foi mantida em álcool $70 \%$ e parte foi utilizada para obtenção de peças diafanizadas e de cortes histológicos.

Folhas inteiras foram tratadas com solução de hidróxido de sódio $5 \%$ e de hipoclorito de sódio $20 \%$, sendo que várias lavagens com água destilada foram efetuadas entre um tratamento e outro; as peças foram desidratadas até o álcool etílico $100 \%$, coradas com safranina utilizando-se solução álcool-xilólica $1 \%$ (Shobe \& Lersten 1967, método modificado por Monteiro et al. 1979) e as lâminas montadas em resina sintética.
Cortes transversais à folha e longitudinais aos hidatódios foram obtidos a mão livre da região mediana das folhas; quando os hidatódios localizavam-se, restritamente, nos terços apical e/ou basal foliares, as secções foram obtidas destas regiões. Os cortes foram corados com verde iodo acético (solução aquosa a $1 \%$ ) e vermelho Congo (solução aquosa 1\%; Dop \& Gautié 1909); as lâminas foram montadas em gelatina glicerinada (Berlyn \& Miksche 1976).

Os diagramas, com as respectivas escalas foram efetuados sob microscópio Carl Zeiss portador de câmara clara.

Os gêneros foram organizados ao nível de tribo de acordo com Heywood et al. (1977).

\section{Resultados e Discussão}

Dentre os oito diferentes tipos de estruturas secretoras já descritos na literatura para folhas de Asteraceae, quatro foram observados nas espécies analisadas: ductos, idioblastos, hidatódios e tricomas. Os dados obtidos estão relacionados nas tabelas 2 e 3, e representados através de diagramas (figuras 1 a 30). A tabela 2 menciona as estruturas secretoras encontradas nos gêneros, que estão citados de acordo com as tribos de Asteraceae, assim como os números das ilustrações referentes a essas estruturas; a tabela 3 apresenta a descrição e a ocorrência, em nível genérico, de 10 tipos de tricomas secretores.

Os ductos são caracterizados por possuírem um lume (espaço alongado em uma única direção), que é circundado por um único estrato de células epiteliais (figuras 1-4). Tais estruturas estão presentes em 39 das 72 espécies, num total de 14 gêneros, abrangendo quatro tribos e ausentes em 33 espécies, dentre oito gêneros, distribuídos em três tribos (tabela 2). Quanto à sua localização, são observados em nervuras ocupando duas posições distintas: a) associados exclusivamente ao floema (figura 1), nas espécies pertencentes ao gênero Baccharis, em Inulopsis scaposa e em Trixis verbasciformis; b) associados ou próximos ao xilema e ao floema (figuras 2 e 4 ) ou exclusivamente ao xilema (figura 3 ), nas espécies dos gêneros Aspilia, Bidens (figura 4), Calea, Eupatorium (figura 2), Mikania (figura 3), Riencourtia, Stevia, Verbesina, Viguiera, Wedelia e Wulffia.

Os idioblastos secretores são células individualizadas que têm conteúdos de aspectos (desde o amorfo e denso até aquele formado por gotas, volumosas ou não) e cores (amareloesverdeada a castanha) variados. Eles são observados em 23 espécies, abrangendo 11 gêneros, 
Tabela 1. Espécies estudadas, acompanhadas de citação da data de coleta, nome e número do coletor, e sigla do herbário.

\begin{tabular}{|c|c|c|c|}
\hline Espécie & Data da coleta & Nome e $\mathrm{n}^{0}$ do coletor & Sigla do herbário \\
\hline Aspilia setosa Griseb. & $14 / 10 / 1980$ & Mantovani 1064 & $(\mathrm{SP})$ \\
\hline Baccharis camporum DC & $05 / 05 / 1980$ & Mantovani 702 & (SP) \\
\hline B. pseudotenuifolia Teodoro & $12 / 12 / 1981$ & Mantovani 1697 & (SP) \\
\hline$B$. sessiliflora Vahl & $06 / 05 / 1980$ & Mantovani 769 & (SP) \\
\hline B. tridentata Vahl & $26 / 05 / 1981$ & Mantovani 1871 & (SP) \\
\hline Bidens gardneri Baker & $29 / 04 / 1981$ & Sugiyama \& Mantovani 201 & (SP) \\
\hline B. graveolens Mart. & $27 / 01 / 1981$ & Mantovani \& Sugiyama 1635 & (SP) \\
\hline Calea clausseniana Baker & $12 / 11 / 1979$ & Mantovani 205 & (SP) \\
\hline C. cuneifolia DC. & $15 / 10 / 1980$ & Mantovani 1159 & (SP) \\
\hline C. platylepis Sch.-Bip. & $18 / 11 / 1980$ & Mantovani 1294 & (SP) \\
\hline Chaptalia integerrima (Vell.) Burk. & $17 / 10 / 1980$ & Mantovani 1235 & (SP) \\
\hline Elephantopus biflorus (Less.) Sch.-Bip. & $18 / 03 / 1981$ & Mantovani \& Oliveira 1734 & (SP) \\
\hline E. elongatus Gardn. & $27 / 04 / 1981$ & Sugiyama \& Mantovani 154 & (SP) \\
\hline E. micropappus Less. & $18 / 03 / 1981$ & Mantovani \& Oliveira 1739 & (SP) \\
\hline Eremanthus sphaerocephalus (DC.) Baker & $24 / 06 / 1980$ & Mantovani 828 & (SP) \\
\hline Eupatorium amigdalinum Lam. & $15 / 09 / 1980$ & Mantovani 952 & (SP) \\
\hline E. campestre DC. & $18 / 11 / 1980$ & Mantovani 1328 & (SP) \\
\hline E. chlorolepsis Baker & $27 / 04 / 1981$ & Mantovani \& Sugiyama 1821 & (SP) \\
\hline E. dictyophyllum DC. & $14 / 11 / 1979$ & Mantovani 260 & (SP) \\
\hline E. horminoides (DC.) Baker & $08 / 04 / 1980$ & Mantovani 567 & (SP) \\
\hline E. intermedium DC. & $18 / 03 / 1981$ & Mantovani \& Oliveira 1764 & (SP) \\
\hline E. laevigatum Lam. & $17 / 03 / 1981$ & Oliveira \& Mantovani 44 & (SP) \\
\hline E. lanigerum Hook. et Arn. & $17 / 03 / 1981$ & Oliveira \& Mantovani 49 & (SP) \\
\hline E. maximiliani Schrad. & $29 / 04 / 1981$ & Sugiyama \& Mantovani 205 & (SP) \\
\hline E. megacephalum Mart. & $07 / 04 / 1980$ & Mantovai 481 & (SP) \\
\hline E. molissimum Baker & $27 / 01 / 1981$ & Sugiyama \& Mantovani 72 & (SP) \\
\hline E. oxylepis DC. & $27 / 04 / 1981$ & Mantovani \& Sugiyama 1828 & (SP) \\
\hline E. purpurascens Sch.-Bip. & $06 / 08 / 1980$ & Mantovani 896 & (SP) \\
\hline E. squalidum DC. & $08 / 04 / 1980$ & Mantovani 609 & (SP) \\
\hline E. stachyophyllum Spreng. & $16 / 09 / 1980$ & Mantovani 1015 & (SP) \\
\hline Gochnatia barrosii Cabrera & $06 / 08 / 1980$ & Mantovani 903 & (SP) \\
\hline G. pulchra Cabrera & $05 / 05 / 1980$ & Mantovani 737 & (SP) \\
\hline Inulopsis scaposa (Baker) Hoffm. & $29 / 08 / 1962$ & Mimura 533 & (SP) \\
\hline Mikania officinalis Mart. & $23 / 12 / 1980$ & Mantovani 1516 & (SP) \\
\hline M. sessilifolia $\mathrm{DC}$. & $06 / 05 / 1980$ & Mantovani 784 & (SP) \\
\hline Piptocarpha rotundifolia (Less.) Baker & $27 / 01 / 1981$ & Sugiyama \& Mantovani 20 & (SP) \\
\hline Pterocaulon alopecuroides (Lam.) DC. & $26 / 01 / 1981$ & Mantovani 1533 & (SP) \\
\hline P. rugosum (Vahl) Malme & $18 / 03 / 1981$ & Mantovani \& Oliveira 1765 & (SP) \\
\hline Riencourtia oblongifolia Gardn. & $22 / 12 / 1980$ & Mantovani 1449 & (SP) \\
\hline Stevia cinerascens Sch.-Bip. & $07 / 04 / 1980$ & Mantovani 484 & (SP) \\
\hline S. comixta Rob. & $26 / 01 / 1981$ & Mantovani 1569 & (SP) \\
\hline S. veronicae DC. & $17 / 03 / 1981$ & Oliveira \& Mantovani 57 & (SP) \\
\hline Trixis glutinosa D. Don & $25 / 06 / 1980$ & Mantovani 837 & (SP) \\
\hline T. verbasciformis Less. & $03 / 03 / 1973$ & Sakane 32 & (SP) \\
\hline Verbesina sordescens DC. & $06 / 02 / 1980$ & Mantovani 440 & (SP) \\
\hline Vernonia apiculada (Sch.-Bip.) Mart. & $08 / 04 / 1980$ & Mantovani 521 & (SP) \\
\hline V. bardanoides Less. & $17 / 03 / 1981$ & Oliveira \& Mantovani 53 & (SP) \\
\hline V. brevifolia Less. & $16 / 09 / 1980$ & Mantovani 1020 & (SP) \\
\hline V. brevipetiolata Sch.-Bip. & $17 / 03 / 1981$ & Oliveira \& Mantovani 66 & (SP) \\
\hline V. cognata Less. & $19 / 11 / 1980$ & Mantovani 1352 & (SP) \\
\hline V. coriacea Less. & $29 / 04 / 1981$ & Sugiyama \& Mantovani 193 & (SP) \\
\hline V. ferruginea Less. & $17 / 07 / 1980$ & Leitão $\mathrm{F}^{\circ}$. \& Martins 11311 & (UEC) \\
\hline V. glabrata Less. & $26 / 01 / 1981$ & Mantovani 1602 & (SP) \\
\hline V. grandiflora Les. & $13 / 11 / 1979$ & Mantovani 225 & (SP) \\
\hline V. herbacea (Vell.) Rusby & $14 / 10 / 1980$ & Mantovani 1098 & (SP) \\
\hline V. holosericea Mart. & $24 / 06 / 1980$ & Mantovani 815 & (SP) \\
\hline V. ignobilis Less. & $17 / 11 / 1980$ & Mantovani 1256 & (SP) \\
\hline V. laevigata Mart. & $27 / 04 / 1981$ & Sugiyama \& Mantovani 134 & (SP) \\
\hline V. lappoides Baker & $17 / 03 / 1981$ & Oliveira \& Mantovani 70 & (SP) \\
\hline V. megapotamica (Sch.-Bip.) Spreng & $12 / 11 / 1979$ & Mantovani 214 & (SP) \\
\hline V. mucronulata Less. & $05 / 08 / 1980$ & Mantovani 865 & (SP) \\
\hline V. obtusata Less. & $27 / 04 / 1981$ & Mantovani \& Sugiyama 1807 & (SP) \\
\hline$V$. onopordioides Baker & $08 / 04 / 1980$ & Mantovani 585 & (SP) \\
\hline V. rubriramea Mart & $27 / 04 / 1981$ & Sugiyama \& Mantovani 160 & (SP) \\
\hline V. tragiaefolia (Sch.-Bip.) DC. & $17 / 10 / 1980$ & Mantovani 1238 & (SP) \\
\hline V. virgulata Mart. & $23 / 06 / 1980$ & Mantovani 795 & (SP) \\
\hline V. zuccariniana Mart. & $07 / 04 / 1980$ & Mantovani 470 & (SP) \\
\hline Viguiera discolor Baker & $14 / 10 / 1980$ & Mantovani 1094 & (SP) \\
\hline V. robusta $\mathrm{Gard}$. & $07 / 04 / 1980$ & Mantovani 505 & (SP) \\
\hline Wedelia macrodonta DC. & $27 / 01 / 1981$ & Mantovani \& Sugiyama 1648 & (SP) \\
\hline W. subvelutina $\mathrm{DC}$. & $17 / 03 / 1981$ & Oliveira \& Mantovani 30 & (SP) \\
\hline Wulffia baccata (Loef.) O. Kuntze & $12 / 02 / 1980$ & Melo \& Chiea 205 & (SP) \\
\hline
\end{tabular}

Observação: todas as espécies foram coletadas na Reserva Biológica da Fazenda Campininha (Moji Guaçu, SP, Brasil), executando-se Inulopsis scaposa (São José dos Campos, SP, Brasil) e Trixis verbasciformis (Campos do Jordão, SP, Brasil). 


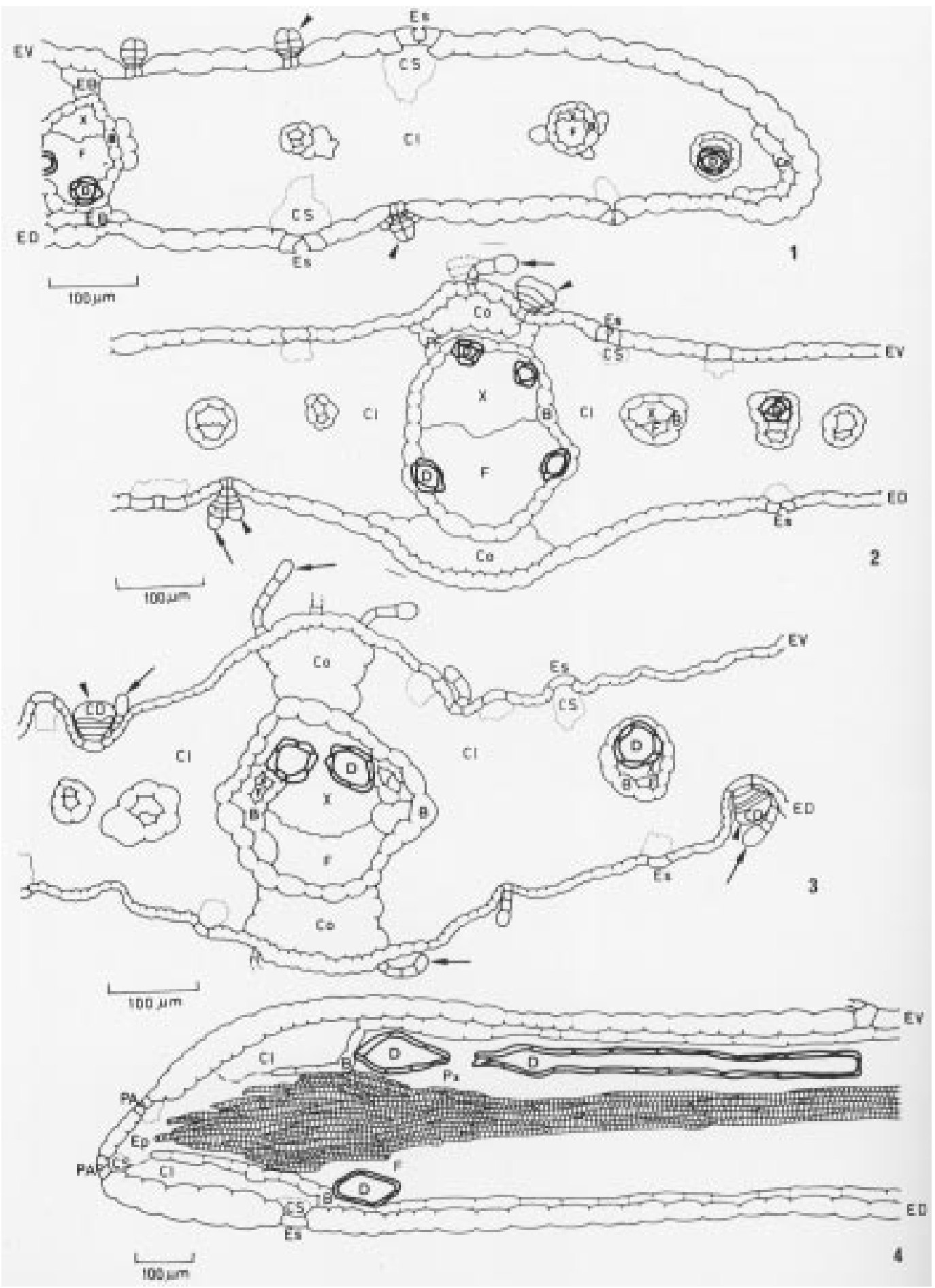

Figuras 1-4. Diagramas de cortes histológicos da região mediana de folhas, evidenciando os ductos secretores. 1-3. Corte transversal. 1. Baccharis sessiliflora Vahl.; 2. Eupatorium laevigatum Lam.; 3. Mikania officinalis Mart., 4. Corte longitudinal - Bidens graveolens Mart., B - bainha; CD - cutícula distendida; Cl - clorênquima; Co - colênquima; CS - câmara subestomática; D - ducto; EB - extensão de bainha; ED - epiderme dorsal; EP - epitema; Es - estômato; EV - epiderme ventral; F - floema; PA - poro aquífero; PF - parênquima fundamental; Px - parênquima xilemático; X - xilema; seta indica tricoma secretor do tipo II e cabeça de seta o do tipo VI. 
distribuídos em quatro tribos e não são encontrados em 49 espécies, totalizando 19 gêneros, nas seis tribos estudadas (tabela 2). Tais estruturas também ocupam posições distintas: a) exclusivamente na nervura principal (no parênquima fundamental e na bainha dos feixes vasculares; figuras 5-8); o conteúdo pode variar quanto ao aspecto: sob a forma de gotas volumosas apenas em Piptocarpha rotundifolia (figura 6), ou de aspecto amorfo e denso em Gochnatia pulchra (figura 5), Eremanthus sphaerocephalus (figura 7) e em três espécies de Vernonia: V. bardanoides, V. brevipetiolata (figura 8) e $V$. ignobilis; b) em nervuras, incluindo a principal (no parênquima fundamental, em extensões de bainha e na bainha dos feixes vasculares), no clorênquima e na epiderme (dorsal, ventral, ou ambas) em quatro espécies de Vernonia: $V$. apiculata, V. ferruginea, V. mucronulata e $V$. rubriramea; c) no clorênquima (parênquima paliçádico, parênquima lacunoso ou ambos; figuras 9 e 10), podendo a ocorrência ter continuidade na epiderme (figura 9), em: Elephantopus biflorus, E. micropappus (figura 9), Eupatorium megacephalum, Mikania sessilifolia, Stevia comixta, Trixis glutinosa, Vernonia cognata, V. glabrata, V. holosericea (figura 10), V. laevigata, V. obtusata, Viguiera discolor e Wedelia subvelutina.

Considerando a morfologia externa das folhas, as margens apresentam-se inteiras em toda a sua extensão nas duas espécies de Gochnatia, em Piptocarpha rotundifolia, Trixis verbasciformis e em duas espécies de Vernonia: V. brevifolia (figura 11) e $V$. virgulata, ou então, em parte inteiras e em parte portando ornamentações (dentes, crenas etc.) nas demais espécies investigadas. Estruturalmente observados nestas ornamentações, os hidatódios estão presentes em 65 espécies, pertencentes a 19 gêneros, distribuídos nas seis tribos (tabela 2). Em

Tabela 2 . Estruturas secretoras em folhas de espécies de Asteraceae do cerrado da Reserva Biológica de Moji Guaçu (SP, Brasil): estrutura presente $(+)$, estrutra de presença duvidosa (?) e estrutura ausente (-)

\begin{tabular}{|c|c|c|c|c|c|c|}
\hline \multirow{2}{*}{$\begin{array}{l}\text { Tribo } \\
\text { Astereae }\end{array}$} & \multicolumn{2}{|c|}{ Gênero (nº de espécies estudadas) } & \multirow{2}{*}{$\begin{array}{c}\begin{array}{c}\text { Ductos } \\
\text { (figuras 1-4) }\end{array} \\
+(4)\end{array}$} & \multirow{2}{*}{$\begin{array}{c}\begin{array}{c}\text { Idioblastos } \\
\text { (figuras 5-10) }\end{array} \\
-(4)\end{array}$} & \multirow{2}{*}{$\begin{array}{c}\begin{array}{c}\text { Hidatódios } \\
\text { (figuras } 4,11-16)\end{array} \\
+(3) ; ?(1)\end{array}$} & \multirow{2}{*}{$\begin{array}{c}\begin{array}{c}\text { Tricomas } \\
\text { (figuras 17-30) }\end{array} \\
+(4)\end{array}$} \\
\hline & Baccharis L. & (4) & & & & \\
\hline & Inulopsis O. Hoffm. & (1) & $+(1)$ & $-(1)$ & $+(1)$ & $-(1)$ \\
\hline \multirow[t]{3}{*}{ Eupatorieae } & Eupatorium L. & $(15)$ & $+(15)$ & $+(1) ;-(14)$ & $+(15)$ & $+(15)$ \\
\hline & Mikania Willd. & (2) & $+(2)$ & $+(1) ;-(1)$ & $+(2)$ & $+(2)$ \\
\hline & Stevia Cav. & (3) & $+(3)$ & $+(1) ;-(2)$ & $+(3)$ & $+(3)$ \\
\hline \multirow[t]{8}{*}{ Heliantheae } & Aspilia Thou & (1) & $+(1)$ & $-(1)$ & $+(1)$ & $+(1)$ \\
\hline & Bidens $\mathrm{L}$ & (2) & $+(2)$ & $-(2)$ & $+(2)$ & $+(2)$ \\
\hline & Calea $\mathrm{L}$ & (3) & $+(3)$ & $-(3)$ & $+(3)$ & $+(3)$ \\
\hline & Riencourtia Cass & (1) & $+(1)$ & $-(1)$ & $+(1)$ & $+(1)$ \\
\hline & Verbesina $\mathrm{L}$. & (1) & $+(1)$ & $-(1)$ & $+(1)$ & $+(1)$ \\
\hline & Viguiera H.B.K. & (2) & $+(2)$ & $+(1) ;-(1)$ & $+(2)$ & $+(2)$ \\
\hline & Wedelia Jacq. & (2) & $+(2)$ & $+(1) ;-(1)$ & $+(2)$ & $+(2)$ \\
\hline & Wulffia Neck. ex Cass. & (1) & $+(1)$ & $-(1)$ & $+(1)$ & $+(1)$ \\
\hline Inuleae & Pterocaulon Elliott & (2) & $-(2)$ & $-(2)$ & $+(2)$ & $+(2)$ \\
\hline \multirow[t]{3}{*}{ Mutisieae } & Chaptalia Vent. & (1) & $-(1)$ & $-(1)$ & $+(1)$ & $+(1)$ \\
\hline & Gochnatia H.B.K. & (2) & $-(2)$ & $+(1) ;-(1)$ & $-(2)$ & $+(2)$ \\
\hline & Trixis P. Browne & (2) & $+(1) ;-(1)$ & $+(1) ;-(1)$ & $+(1) ;-(1)$ & $+(2)$ \\
\hline \multirow[t]{4}{*}{ Vernonieae } & Elephantopus L. & (3) & $-(3)$ & $+(2) ;-(1)$ & $+(3)$ & $+(3)$ \\
\hline & Eremanthus Less. & (1) & $-(1)$ & $+(1)$ & $+(1)$ & $+(1)$ \\
\hline & Piptocarpha R. Br. & (1) & $-(1)$ & $+(1)$ & $-(1)$ & $+(1)$ \\
\hline & Vernonia Schreb. & (22) & $-(22)$ & $+(12) ;-(10)$ & $+(22)$ & $+(22)$ \\
\hline
\end{tabular}

Obs: tribos de acordo com Heywood et al. (1977). 


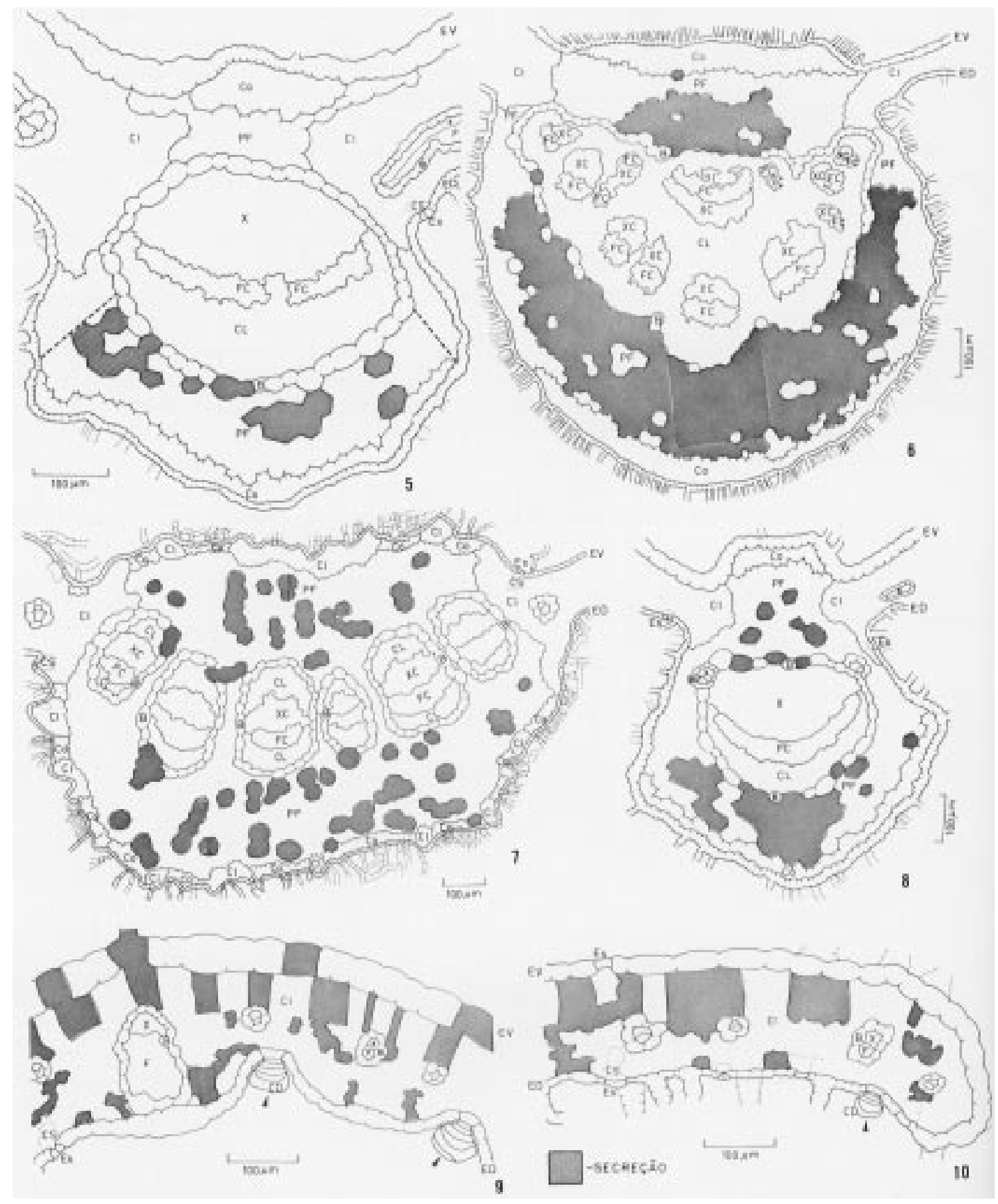

Figuras 5-10. Diagramas de cortes transversais da região mediana de folhas nos quais os idioblastos são visualizados. 5. Gochnatia pulchra Cabrera. - nervura principal; linhas tracejadas delimitam a região na qual os idioblastos são encontrados; 6. Piptocarpha rotundifolia (Less.) Baker:: nervura principal; 7. Eremanthus sphaerocephalus (DC.) Baker.: nervura principal; 8. Vernonia brevipetiolata Sch.-Bip.: nervura principal; 9. Elephantopus micropappus Less.; 10. Vernonia holosericea Mart.. B - bainha; CD - cutícula distendida; CL - células de paredes lignificadas; Cl - clorênquima; Co - colênquima; CS - câmara subestomática; ED - epiderme dorsal; Es - estômato; EV - epiderme ventral; F - floema; FC - floema (elementos condutores); PF - parênquima fundamental; X - xilema; XC - xilema (elementos condutores); cabeça de seta indica tricoma secretor do tipo VI. 
Tabela 3. Descrição e ocorrência dos tipos de tricomas secretores em folhas de espécies de Asteraceae do cerrado da Reserva Biológica de Moji Guaçu (SP, Brasil).

\begin{tabular}{|c|c|c|c|}
\hline Tipo & Descrição & Ocorrência (em nível genérico) & Figura(s) \\
\hline $\mathrm{I}$ & $\begin{array}{l}\text { unisseriado, capitado, com } 4-5 \text { células; a cabeça é formada de } 1 \text { célula } \\
\text { semiglobóide e tem conteúdo de aspecto denso; a célula distal pode } \\
\text { apresentar-se infectada, talvez por fungos. }\end{array}$ & Vernonia & 17 e 18 \\
\hline II & $\begin{array}{l}\text { unisseriado, filamentoso, recurvado ou não, com número variável de } \\
\text { células; a forma da célula distal varia de globóide a espatulada, tendo } \\
\text { aspecto hialino. }\end{array}$ & $\begin{array}{l}\text { Aspilia; Bidens; Calea; Eupatorium; } \\
\text { Mikania; Riencourtia; Stevia; Verbe- } \\
\text { sina; Viguiera; Wedelia; Wulffia }\end{array}$ & $19-21$ \\
\hline III & $\begin{array}{l}\text { unisseriado, filamentoso, capitado, ereta, com número variável de cé- } \\
\text { lulas, tendo a cabeça } 1 \text { ou } 2 \text { células; a célula distal é semiglobóide e } \\
\text { tem conteúdo de aspecto denso. }\end{array}$ & Trixis & 22 \\
\hline IV & $\begin{array}{l}\text { unisseriado, filamentoso, capitado, ereto, com número variável de cé- } \\
\text { lulas, tendo a cabeça } 1 \text { célula semiglobóide; não foi observada a pre- } \\
\text { sença de conteúdo de aspecto denso. }\end{array}$ & Trixis & 23 \\
\hline $\mathrm{V}$ & $\begin{array}{l}\text { bisseriado, globóide, com 3-9 células; a porção distal do tricoma pode } \\
\text { ter } 1 \text { ou } 2 \text { células, que têm conteúdo de aspecto denso. }\end{array}$ & Bidens & 24 \\
\hline VI & $\begin{array}{l}\text { bisseriado, capitado, com 8-12 células; a cabeça é formada de 6-10 cé- } \\
\text { lulas, tendo as distais conteúdo de aspecto denso; a secreção pode ser } \\
\text { encontrada no espaço subcuticular. }\end{array}$ & $\begin{array}{l}\text { Baccharis; Calea; Elephantopus; Ere- } \\
\text { manthus; Eupatorium; Gochnatia; Mi- } \\
\text { kania; Piptocarpha; Pterocaulon; Ste- } \\
\text { via; Vernonia; Viguiera; Wedelia; Wul- } \\
\text { ffia. }\end{array}$ & 25 \\
\hline VII & $\begin{array}{l}\text { bisseriado, capitado, em forma de bastão, com } 14-16 \text { células; a cabeça é } \\
\text { formada de } 12-14 \text { células, as distais têm conteúdo de aspecto denso. }\end{array}$ & Gochnatia & 26 \\
\hline VIII & $\begin{array}{l}\text { bisseriado, filamentoso, ereto, com } 8-14 \text { células; as distais apresentam } \\
\text { constrição na porção basal e têm conteúdo de aspecto denso. }\end{array}$ & Aspilia & 27 \\
\hline IX & $\begin{array}{l}\text { em parte bi e em parte multisseriado, capitado, com número variável. } \\
\text { de células; a cabeça é multisseriada, com número variável de células, que } \\
\text { possuem conteúdo de aspecto denso. }\end{array}$ & Chaptalia & 28 e 29 \\
\hline $\mathrm{X}$ & $\begin{array}{l}\text { bisseriado, filamentoso, capitado, ereto, com número variável de célu- } \\
\text { las; a cabeça é formada por } 8-18 \text { células e as distais têm conteúdo de } \\
\text { aspecto denso. }\end{array}$ & Eupatorium & 30 \\
\hline
\end{tabular}

corte longitudinal, as margens foliares são planas (figura 13), revolutas sem saliência na face ventral (figura 12), ou ainda, revolutas com saliência na face ventral (figuras 14-16). Os hidatódios são caracterizados pela presença de poros aqüíferos que se assemelham a estômatos (Fahn 1979, Lersten \& Curtis 1985), epitema, elementos de condução exclusivamente xilemáticos e bainha do feixe aberta (figuras 4 e 12-16); no caso em que as margens são revolutas com saliência na face ventral, os elementos de condução xilemáticos estendem-se para ambas as faces da folha, aspecto observado em Elephantopus elongatus (figuras 14 e 15) ou apenas para a face ventral, nas duas espécies de Pterocaulon (figura 16). Dúvida permanece quanto à presença de hidatódios em Baccharis camporum, pois as estruturas encontradas nas ornamentações possuem elementos de condução exclusivamente xilemáticos e bainha do feixe aberta; porém, não portam nem poros aqüíferos nem epitema. Eles não são observados em quatro espécies, dentre três gêneros, pertencentes a duas tribos (tabela 2).

Os tricomas secretores são apêndices epidérmicos que se distinguem por apresentar células que liberam substâncias de aspecto denso ou hialino; este material pode permanecer dentro do protoplasto destas células, ou então, ser liberado para o espaço subcuticular, que se formou pela distensão da cutícula. Tais estruturas estão registradas para 71 espécies, perfazendo um total de 20 gêneros, distribuídos nas seis tribos (tabela 2); eles não estão presentes apenas em Inulopsis scaposa. A variação estrutural encontrada nesses apêndices possibilita a identificação de 10 diferentes tipos (figuras 17-30), que estão descritos na tabela 3.

Avaliados conjuntamenle, os tipos de estruturas secretoras encontrados e a posição que ocupam nos órgãos foliares têm valor diagnóstico em nível genérico, o que permitiu a identificação de gêneros através de uma chave que é apresentada a seguir. 
Chave, baseada especialmente em estruturas secretoras, para identificação dos gêneros de Asteraceae do cerrado da Reserva Biológica de Moji Guaçu, SP, Brasil (As figuras mencionadas ilustram os aspectos anatômicos que estão sendo relevados):

1. Ductos presentes em folhas (figuras 1-4)

2. Ductos, em nervuras, associados exclusivamente ao floema (figura 1)

3. Tricomas secretores ausentes Inulopsis

3. Tricomas secretores presentes

4. Tricomas do tipo VI (figuras 1 e 25) Baccharis

4. Tricomas dos tipos III e IV (figuras 22 e 23) Trixis

2. Ductos, em nervuras, associados ou próximos ao xilema e ao floema.

(figuras 2 e 4 ) ou associados exclusivamente ao xilema (figura 3 )

5. Tricomas secretores do tipo V (figura 24) Bidens

5. Tricomas secretores de outro tipo

6. Tricomas do tipo VIII (figura 27) Aspilia

6. Tricomas de outro tipo

7. Tricomas do tipo II, do tipo VI ou ambos os tipos (figuras 19-21,25) Calea, Eupatorium, Mikania, Riencourtia, Stevia,

7. Tricomas do tipo $X$ Verbesina, Viguiera, Wedelia, Wulffia Eupatorium

1. Ductos ausentes em folhas (figura 5-16)

8. Folhas com margem inteira em toda a sua extensão

9. Hidatódio restrito ao ápice da folha (figura 11) Vernonia

9. Hidatódios ausentes

10. Idioblastos ausentes Gochnatia

10. Idioblastos presentes exclusivamente na nervura principal (figuras 5 e 6 )

11. Idioblastos com conteúdo de aspecto amorfo e denso (figura 5) Gochnatia

11. Idioblastos portadores de gotas volumosas (figura 6)

8. Folhas com margem em parte inteira e em parte portando ornamentações, hidatódios presentes (figuras 12-16)

12. Tricomas secretoras do tipo III Trixis

12. Tricomas secretores de outro tipo

13. Tricomas do tipo IX (figura 28 e 29) Chaptalia

13. Tricomas do tipo VI (figura 25)

14. Idioblastos presentes, com conteúdo de aspecto amorfo e denso (figura 7-10)

15. Idioblastos presentes em nervuras, no parênquima fundamental e bainha dos feixes (figura 7 e 8 ) Eremanthus, Vernonia

15. Idioblastos ausentes em nervuras, presentes no clorênquima (figuras 9 e 10) Elephantopus, Vernonia

14. Idioblastos ausentes (figuras 1-4 e 12-16)

16. Margem plana (figura 13) ou revoluta sem saliência na face ventral (figura 12) Vernonia

16. Margem revoluta com saliência na face ventral (figuras 14-16)

17. Elementos de condução xilemáticos do hidatódio estendidos a ambas as faces (figuras 14 e 15)

17. Elementos de condução xilemáticos do hidatódio estendidos, apenas, à face ventral (figura 16) 


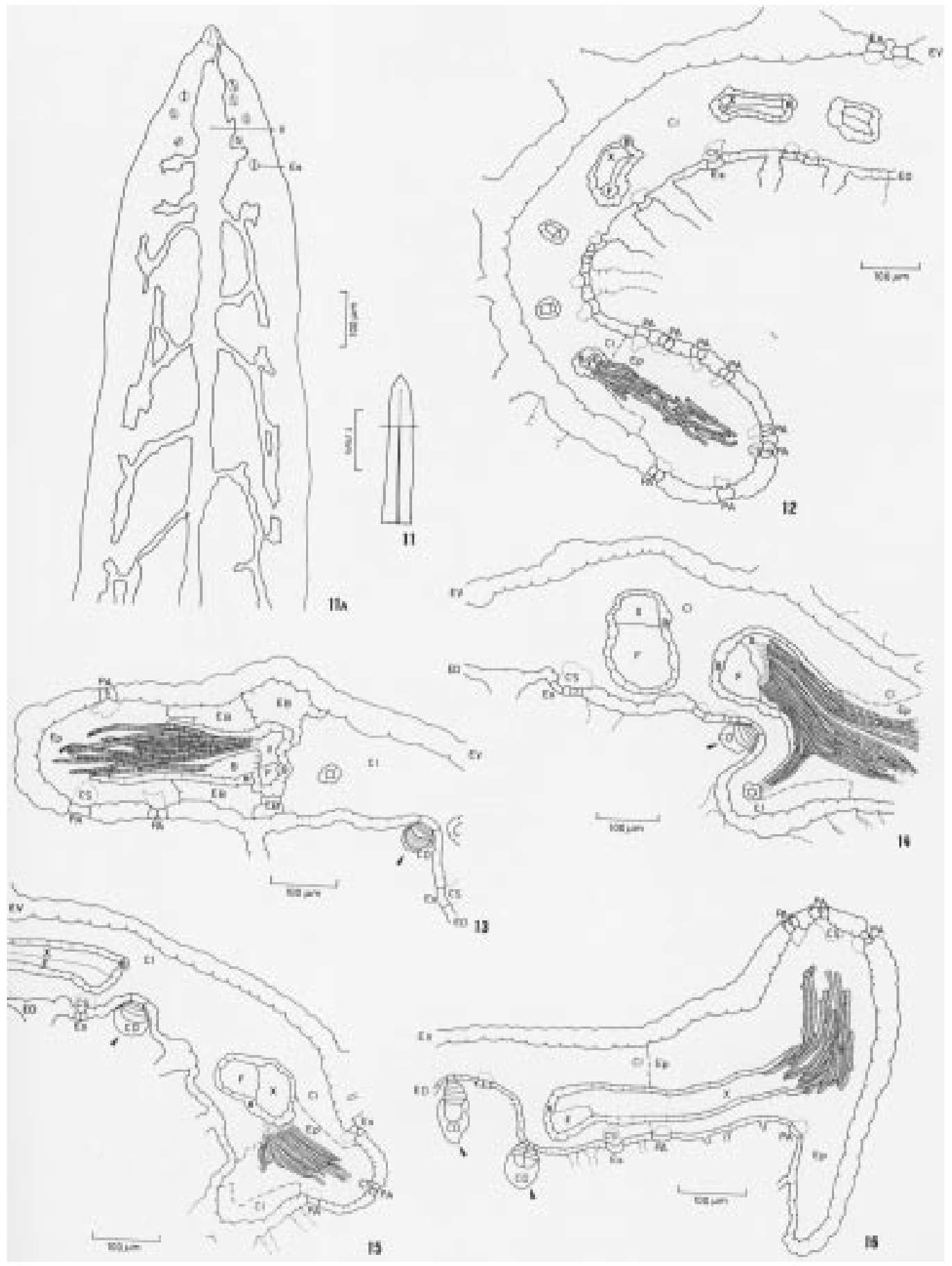

Figuras 11-16. Diagramas de folhas, evidenciando hidatódios. 11. Folha inteira; 12-16. Corte longitudinal do hidatódio localizado na região mediana da folha. 11. Vernonia brevifolia Less. 11A. Pormenor da região delimitada na figura 11; vista frontal do ápice da folha; 12 . Vernonia herbacea (Vell.) Rusby.; 13. Vernonia lappoides Baker.; 14-15. Elephantopus elongatus Gardn.; 16. Pterocaulon alopecuroides (Lam.) DC. B - bainha; CD - cutícula distendida; $\mathrm{Cl}$ - clorênquima; $\mathrm{CS}$ - câmara subestomática; EB - extensão de bainha; ED - epiderme dorsal; Ep - epitema; Es - estômato; EV - epiderme ventral; F - floema; PA - poro aquífero; V - venação; X - xilema; cabeça de seta indica tricoma secretor do tipo VI. 


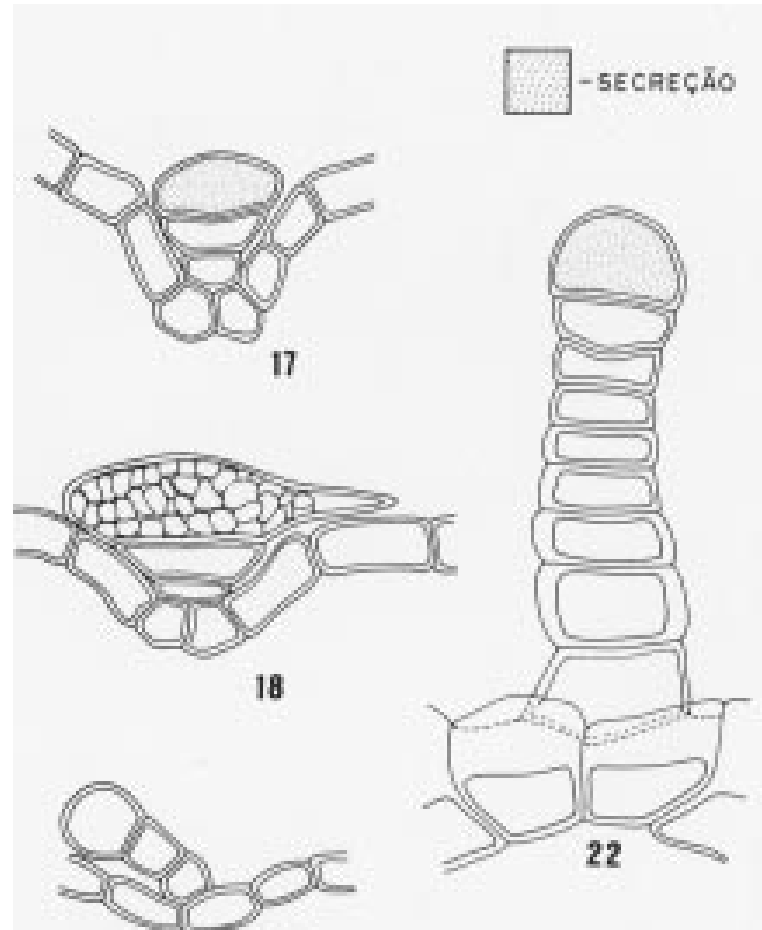

19

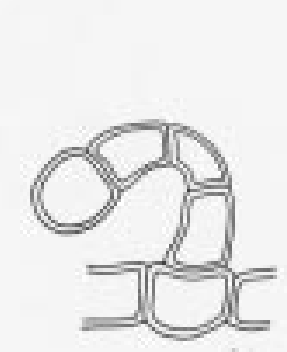

20

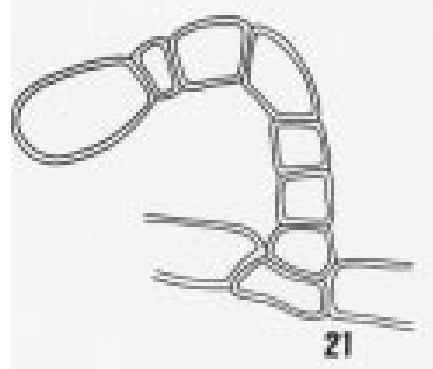

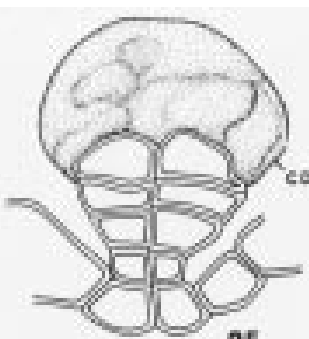

25
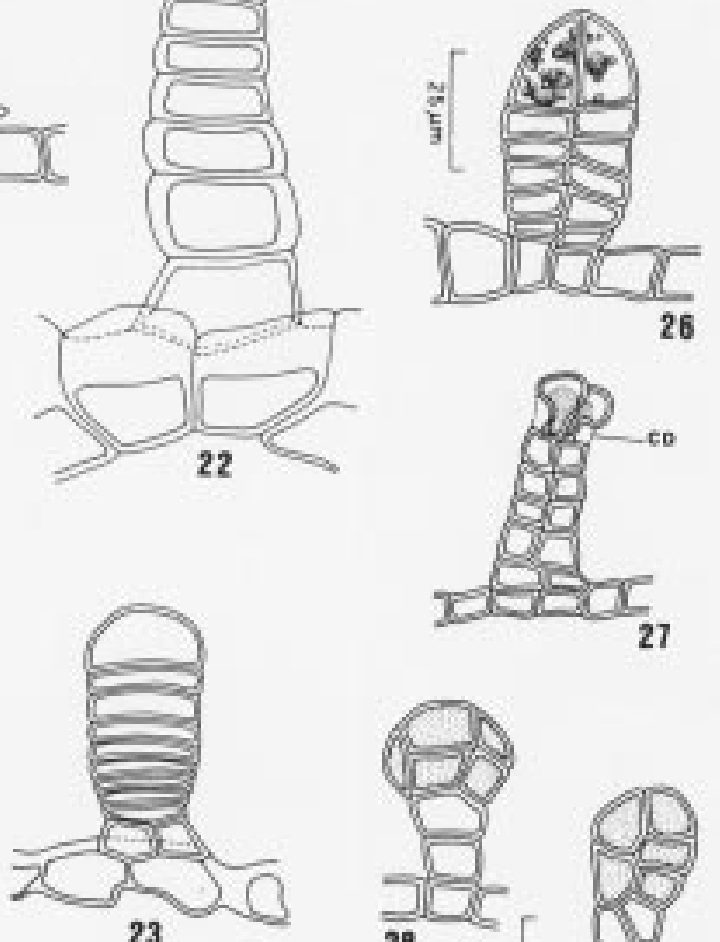

23

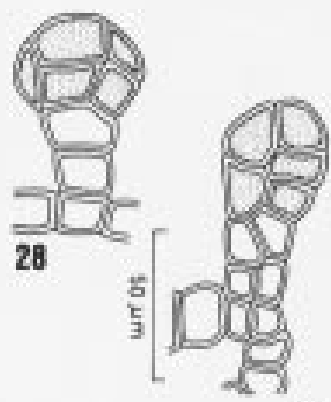

29

Figuras 17-30. Tipos de tricomas secretores, 17-18. Tipo I, Vernonia rubriramea Mart. 18. Aspecto da deformação, quando ocupado por certos microrganismos (talvez fungos). 19-21. Tipo II. 19. Mikania officinalis Mart.; 20. Eupatorium laevigatum Lam.; 21. Eupatorium dictyophyllum DC. 22. Tipo III, Trixis glutinosa D. Don.; 23. Tipo IV, Trixis verbasciformis Less.; 24. Tipo V, Bidens graveolens Mart.; 25. Tipo VI, Stevia comixta Rob.; 26. Tipo VII, Gochnatia barrosii Cabrera.; 27. Tipo VIII, Aspilia setosa Griseb. 28-29. Tipo IX, Chaptalia integerrina (Vell.) Burk.; 30. Tipo X, Eupatorium amigdalinum Lam.. CD - cutícula distendida. 
O valor diagnóstico das estruturas secretoras em folhas tem sido evidenciado para gêneros pertencentes a outras famílias de Angiospermas. Por exemplo, a distribuição mutuamente exclusiva de dois tipos de idioblastos, diferentes entre si quanto ao formato e à posição que ocupam na lâmina foliar, foi considerada um caracter taxonômico significante para confirmar o conceito de que Parkinsonia e Cercidium (Leguminosae - Caesalpinioideae) são entidades taxonômicas distintas (Lersten \& Curtis 1995). Em espécies de Caesalpinia (LeguminosaeCaesalpinioideae), a presença de cavidades e de idioblastos, e o padrão de distribuição dos idioblastos em folhas podem ser considerados como caracteres importantes em nível subgenérico e de grupo (Lersten \& Curtis 1994).

Investigando plantas xeromórficas do leste da Patagônia, Pyykko (1966) concluiu que as estruturas secretoras têm significado taxonômico, sendo mais características em certas famílias e gêneros do que em grupos ecológicos. A presença de ductos (designados canais pelo autor), idioblastos e tricomas secretores foi registrada ao serem examinadas folhas de 284 espécies pertencentes a 50 famílias dentre as fanerógamas; entre elas, estavam as Asteraceae com 61 representantes. Ainda segundo Pyykko (1966), os canais parecem estar limitados mais a certas famílias (seis dentre as 50) e gêneros (18 dentre os 147 estudados) do que a qualquer grupo ecológico - quatro formações: mata pluvial, steppe, semideserto e monte - tendo somente significado sistemático: os idioblastos parecem ser característicos de certos gêneros (24 dentre os 147 estudados) e alguns tipos de tricomas, incluídos os secretores, podem ser peculiares a umas poucas famílias ou gêneros, enquanto que outros tipos podem ser de ampla ocorrência. Nas Asteraceae, canais secretores foram observados em 24 espécies e tricomas secretores em 17 espécies.

Quanto aos dados do presente trabalho, além de propiciar a possibilidade de elaboração de uma chave em nível genérico para a vegetação estudada, ainda permitem certas considerações em nível de tribo. Uma possível afinidade entre as tribos Eupatorieae e Heliantheae é indicada pela constância na presença e posição ocupada pelos ductos, assim como na presença de tricomas do tipo II exclusivamente nos seus representantes (tabela 3). Na tribo Vernonieae, a constância na ausência de ductos e na presença de tricomas do tipo VI evidencia a homogeneidade existente nos seus elementos constitutivos.

Agradecimentos - À FAPESP, pela concessão de bolsa de doutoramento (processo no 83/1845-7) e à Curadoria do Herbário do Instituto de Botânica (SP), pela permissão em utilizar o material herborizado da Reserva Biológica de Moji Guaçu para os estudos anatômicos.

\section{Referências bibliográficas}

ASCENSÃO, L. \& PAIS, M.S. 1982. Secretory trichomes of Artemisia crithmifolia. Some ultrastructural aspects. Bull. Soc. Bot. Fr. 129 Act. Bot. 1:83-87.

ASCENSÃO, L. \& PAIS, M.S. 1987. Glandular trichomes of Artemisia campestris (ssp. maritima): ontogeny and histochemistry of the secretory product. Bot. Gaz. 148:221-227.

ASCENSÃO, L. \& PAIS, M.S. 1988. Ultrastructure and histochemistry of the secretory ducts in Artemisia campestris ssp. maritima (Compositae). Nord. J. Bot. 8:283-292.

BERLYN, G.P. \& MIKSCHE, J.P. 1976. Botanical microtechnique and cytochemistry. The Iowa State University Press, Ames.

CARLQUIST, S. 1958. Structure and ontogeny of glandular trichomes of Madinae (Compositae). Am. J. Bot. 45:675-682.

CARLQUIST, S. 1959a. The leaf of Calycadenia and its glandular appendages. Am. J. Bot. 46:70-80.

CARLQUIST, S. 1959b. Glandular structures of Holocarpha and their ontogeny. Am. J. Bot. 46:300-308.

CASTRO, M. de M. 1987. Estruturas secretoras em folhas de espécies da família Asteraceae: aspectos estruturais e histoquímicos. Tese de doutorado, Universidade de São Paulo, São Paulo.

CLARO, S.M.C.A. 1994. Levantamento dos tipos de estruturas secretoras em folhas de Asteraceae da restinga de Setiba, Guarapari (ES). Tese de mestrado, Universidade Estadual de Campinas, Campinas.

CURTIS, J.D. \& LERSTEN, N.R. 1986. Development of bicellular foliar secretory cavities in white snakeroot, Eupatorium rugosum (Asteraceae). Am. J. Bot. 73:79-86.

CURTIS, J.D. \& LERSTEN, N.R. 1990. Oil reservoirs in stem, rhizome, and root of Solidago canadensis (Asteraceae, tribe Astereae). Nord. J. Bot. 10:443-449.

CUTTER, E.G. 1978. Plant anatomy. Part I. Cells and tissues. Edward Arnold, London.

DOAIGEY, A.R. \& HARKISS, K.J. 1991. Application of epidermal characters to the taxonomy of european species of Antirrhinum (Schrophulariaceae). Nord. J. Bot. 11:513-524.

DOP, P. \& GAUTIÉ, A. 1909. Manuel de technique botanique. Histologie et microbie végétales (F.R. de Rudeval, ed.). Librairie Scientifique et Littéraire, Paris.

DUKE, S.O. \& PAUL, R.N. 1993 Development and fine structure of the glandular trichomes of Artemisia аппиа $\mathrm{L}$. Int. J. Plant Sci. 154:107-118.

ESAU, K.1977. Anatomy of seed plants. John Wiley \& Sons Inc., New York.

FAHN, A. 1979. Secretory tissues in plants. Academic Press Inc., London.

FAHN, A. 1988. Secretory tissues in vascular plants. New Phytol. 108:229-257. 
FUEYO, G.M. del. 1986. Ontogenia de las glándulas foliares e involucrales de Tagetes minuta (Compositae). Bol. Soc. argent. Bot. 24:403-410.

HEYWOOD, V.H., HARBORNE, J.B. \& TURNER, B.L. 1977. The biology and chemistry of the Compositae. Vols. I, II. Academic Press Inc., London.

JOSEPH, J.P., SHAH, J.J. \& INAMDAR, J.A. 1988. Distribution, development and structure of resin ducts in guayule (Parthenium argentatum Gray). Ann. Bot. 61:377-387.

KELSEY, R.G. 1984. Glandular trichomes: a helpful taxonomic character of Artemisia nova (Black sagebrush). J. Range Manage 37:370-372.

KELSEY, R.G. \& SHAFIZADEH, F. 1980. Glandular trichomes and sesquiterpene lactones of Artemisia nova (Asteraceae). Biochem. Syst. Ecol. 8:371-377.

LERSTEN, N.R. \& CURTIS, J.D. 1985. Distribution and anatomy of hydathodes in Asteraceae. Bot. Gaz. 146:106-114.

LERSTEN, N.R. \& CURTIS, J.D. 1986. Tubular cavities in white snakeroot, Eupatorium rugosum (Asteraceae). Am. J. Bot. 73:1016-1021.

LERSTEN, N.R. \& CURTIS, J.D. 1987. Internal secretory spaces in Asteraceae. A review and original observations on Conyza canadensis (tribe Astereae). La Cellule 74:179-196.

LERSTEN, N.R. \& CURTIS, J.D. 1988. Secretory reservoirs (ducts) of two kinds in giant ragweed (Ambrosia trifida; Asteraceae). Am. J. Bot. 75:1313-1323.

LERSTEN, N.R. \& CURTIS, J.D. 1989. Foliar oil reservoir anatomy and distribution in Solidago canadensis (Asteraceae, tribe Astereae). Nord. J. Bot. 9:281-287.

LERSTEN, N.R. \& CURTIS, J.D. 1993. Subepidermal idioblasts in leaflets of Caesalpinia pulcherrima and Parkinsonia aculeata (Leguminosae: Caesalpinioideae). Bull. Torrey Bot. Club 120:319-326.

LERSTEN, N.R. \& CURTIS, J.D. 1994. Leaf anatomy in Caesalpinia and Hoffmannseggia (Leguminosae, Caesalpinioideae) with emphasis on secretory structures. Pl. Syst. Evol. 192:231-255.

LERSTEN, N.R. \& CURTIS, J.D. 1995. Two foliar idioblasts of taxonomic significance in Cercidium and Parkinsonia (Leguminoseae: Caesalpinioideae). Am. J. Bot. 82:565570.

LÜTTGE, U. 1971. Structure and function of plant glands. Annu. Rev. Pl. Physiol. 22:23-44.

MAKSYMOWYCH, R. \& LEDBETTER, M.C. 1987. Fine structure of epithelial canal cells in petioles of Xanthium pennsylvanicum. Am. J. Bot. 74:65-73.

MALECI, L.B. \& MARCHI, A.B. 1983. "Artemisia vulgaris" L. ed. "A. verlotiorum" Lamotte: studio di alcuni caratteri morfo-anatomici distintivi delle due specie. Webbia 37:185-196.

MALECI, L.B. \& SERVETTAZ, O. 1991. Morphology and distribution of trichomes in italian species of Teucrium sect. Chamaedrys (Labiatae) - a taxonomical evaluation. Pl. Syst. Evol. 174:83-91.
MANTOVANI, W. \& MARTINS, F.R. 1993. Florística do cerrado na Reserva Biológica de Moji Guaçu, SP. Acta bot. bras. 7:33-60.

MEIRA, R.M.S.A. 1991. Levantamento dos tipos de estruturas secretoras em folhas de espécies de Asteraceae em vegetação de floresta (Atibaia, SP). Tese de mestrado, Universidade Estadual de Campinas, Campinas.

METCALFE, C.R. \& CHALK, L. 1950. Anatomy of the Dicotyledons: leaves, stem and wood in relation to taxonomy with notes on economic uses. Vols. I, II. Clarendon Press, Oxford.

MONTEIRO, W.R. 1986. Estruturas secretoras da folha de Porophyllum lanceolatum DC. (Asteraceae): estudos morfológicos, histoquímicos e ultra-estruturais. Tese de livre-docência. Universidade de São Paulo, São Paulo.

MONTEIRO, W.R., GIULIETTI, A.M., MAZZONI, S.C. \& CASTRO, M. de M. 1979. Hairs on reproductive organs of some Eriocaulaceae and their taxonomic significance. Bol. Botânica, Univ. S. Paulo 7:43-59.

MONTEIRO, W.R., CASTRO, M. de M. \& FAHN, A. 1995. Observations on the development of the foliar secretory cavities of Porophyllum lanceolatum (Asteraceae). Nord. J. Bot. 15:69-76.

O'DOWD, D.J. \& CATCHPOLE, E.A. 1983. Ants and extrafloral nectaries: no evidence for plant protection in Helichrysum spp. - ant interactions. Oecologia 59:191-200.

PERRIN, A. 1971. Présence de "cellules de transfert" au sein de l'épithème de quelques hydathodes. Z. Pflanzenphysiol. 65:39-51.

PYYKKO, M. 1966. The leaf anatomy of east Patagonian xeromorphic plants. Ann. Bot. Fenn. 3:453-622.

SCHNEPF, E. 1974. Gland cells. In Dynamic aspects of plant ultrastructure (A.W. Robards, ed.). McGraw-Hill Book Co. Ltd., Maidenhead, p.331-357.

SMITH, F.H. \& SMITH, E.C. 1942. Anatomy of the inferior ovary of Darbya. Am. J. Bot. 29:464-471.

SOLEREDER, H. 1908. Systematic anatomy of the Dicotyledons. A handbook for laboratories of pure and applied Botany. Transl. by L. A. Boodle \& F. G Fritsch. Vols. I, II. Clarendon Press, Oxford.

VERTREES, G.L. \& MAHLBERG, P.G. 1978. Structure and ontogeny of laticifers in Cichorium intybus (Compositae). Am. J. Bot. 65:764-771.

WERKER, E. \& FAHN, A. 1981. Secretory hairs of Inula viscosa (L.) Ait. - development, ultrastructure and secretion. Bot. Gaz. 142:461-476.

WERKER, E. \& FAHN, A. 1982. Inula hairs - structure, ultrastructure and secretion. In Aromatic plants: basic and applied aspects. World crops: production, utilization and description, v. 7 (N. Margaris, A. Koedman \& D. Vokou, eds.). Martinus Nijhoff Publishers, The Hague, p.25-37. 